\title{
Manuais didáticos no início do século XX em Sergipe: cultura material escolar dos grupos escolares
}

\section{Textbooks from the early $20^{\text {th }}$ century in Sergipe: \\ Institutional teaching material for school groups}

Crislane Barbosa AZEVEDO*

Resumo: Ao investigar a cultura escolar dos grupos escolares sergipanos, questionou-se acerca da presença de manuais didáticos nestas instituições no início do século XX e suas características. Assim, com base em pesquisa bibliográfica e documental desenvolvidas sob a perspectiva da História Cultural, objetivou-se identificar quais manuais didáticos integraram a cultura dos grupos escolares, analisar a materialidade dos documentos e identificar aspectos característicos da cultura escolar do período, por meio da análise do conteúdo dos textos dos manuais escolares.

Palavras-chave: Manuais escolares. Grupos escolares. Sergipe.

\begin{abstract}
When investigating the school institutions of Sergipe, the presence and characteristics of textbooks at the beginning of the twentieth century were examined. Thus, based on a literary and documentary search developed from the perspective of Cultural History, the objective was to identify which textbooks had been integrated into the school institutions, then analyze the materiality of the documents, identifying characteristic features of the school institutions of that period through an analysis of the content of the textbooks.
\end{abstract}

Keywords: Textbooks. School institutions. Sergipe.

Os manuais didáticos constituem-se em instrumentos centrais nos processos de escolarização. Independente de aspectos físicos como formato, ilustrações, encadernação, ou de características de conteúdo, os manuais têm ocupado espaço significativo nos sistemas nacionais de educação. Esse fato deixa evidente a importância de pesquisas acerca da história dos livros

\footnotetext{
* Professora Doutora - Departamento de Práticas Educacionais e Currículo - Centro de Educação - UFRN - Campus Natal - Campus Universitário, s/n - Lagoa Nova CEP: 59072-970, Natal-RN, Brasil. E-mail: crislaneazevedo@yahoo.com.br
} 
Manuais didáticos no início do século XX em Sergipe: cultura material escolar dos

grupos escolares

escolares no processo de reconstrução da história da escola e dos procedimentos de ensino e aprendizagem e, portanto, da História da Educação.

Vive-se, atualmente, um processo de disseminação do acesso à internet. Em consequência desse fato, torna-se importante o desenvolvimento de reflexões acerca dos meios de informação (tipos e suportes) e de aprendizagem. Hoje, o livro não é mais apenas o manual impresso, pode-se ler uma obra no formato de livro eletrônico. Isso leva a existência de questionamentos acerca, por exemplo, do futuro do livro escolar impresso. Essas condições, de fato, colaboram para deixar clara a relevância da análise dos manuais didáticos. Da mesma maneira, não se pode deixar de considerar esses manuais exemplos de patrimônio cultural e, como tais, bens a serem conservados.

Pesquisas atuais na área de História da Educação, especialmente as dedicadas à cultura escolar e desenvolvidas sob a perspectiva da História Cultural, têm registrado iniciativas de tal conservação. Em decorrência das mudanças operadas na historiografia mundial, nas últimas décadas, das quais se pode citar a ampliação dos objetos de análise e dos tipos de fontes de pesquisas, os manuais didáticos passaram a ser considerados importantes fontes de investigação e não apenas acerca da escola, mas também da história dos impressos. Nesse sentido, a presente pesquisa dedica-se à análise de manuais didáticos utilizados nos grupos escolares de Sergipe por alunos e professoras, no início do século XX.

Os grupos escolares foram inaugurados em Sergipe no ano de 1911 com o intuito de pôr fim a problemas no ensino primário. Por seu intermédio, procurava-se promover melhorias nos métodos de ensino, na qualificação dos professores e nos recursos didáticos. Em relação a estes podem ser citados os manuais escolares. Tomando-se por base as reflexões relativas à cultura escolar dos grupos, tornou-se consequente o questionamento acerca de quais manuais didáticos estiveram presentes nos grupos sergipanos no início do século $\mathrm{XX}$, bem como quais as suas principais características. Dessa forma é que, nesta pesquisa, objetivou-se identificar quais manuais didáticos integraram a cultura dos grupos escolares, analisar a materialidade dos documentos (formato, dimensões, configuração dos textos, entre outros aspectos) e identificar aspectos característicos de uma cultura escolar de uma determinada época por meio da análise do conteúdo dos textos dos livros escolares.

Para tanto, foi desenvolvida pesquisa bibliográfica acerca da educação brasileira e de manuais didáticos e investigação documental, com atenção a documentos dos antigos grupos escolares, nos quais foram encontradas referências a livros escolares. A análise adotou a abordagem da História Cultural por compreender que essa perspectiva potencializa os manuais como fonte. Com base na pesquisa documental, até o momento realizada, foram localizados manuais voltados 
para áreas de História, Corografia, Língua Portuguesa e Valores, os quais se tornaram alvo da presente análise.

Nesta investigação, não foi realizada análise relativa aos aspectos ideológicos dos manuais. O estudo dos textos e da materialidade das obras foi o foco. Fica claro, assim, que não se dedicou espaço para o exame do processo de circulação e consumo destes documentos. A pesquisa documental (ofícios, relatórios de visita, livro de matrículas) realizada nas instituições de pesquisa do Estado de Sergipe não proporcionou meios para o estudo da difusão e dos usos dos manuais didáticos impressos. Determinar o número de livros produzidos ou enviados aos grupos ou mesmo referências dos usos feitos das obras didáticas por alunos e professoras das instituições de ensino, por exemplo, não foram possíveis.

Como ocorreu em outros Estados do país, em Sergipe também esteve presente a dominação oligárquica conservadora. Mas, em meio a tal predomínio político, houve administradores que contribuíram para o crescimento do Estado, alguns se voltando até para necessidades públicas mais gerais, como a instrução. Ainda que houvesse privilégios para os grupos dominantes, a vida social movimentava-se no Estado, tanto pela melhoria dos serviços prestados à população, quanto pela organização da mesma na publicação de jornais, na realização de greves, nas discussões sobre educação escolar e na fundação de entidades culturais.

Como símbolo de um processo modernizador na vida dos sergipanos, ocorreu em 1911 a reforma da instrução pública responsável pela implantação dos grupos escolares. A escola primária, alvo das discussões sobre os assuntos educacionais na passagem do século XIX para o XX, passou por reformas em seus métodos, com destaque para a adoção do chamado método intuitivo, o qual orientou o ensino nos grupos escolares sergipanos. Esse método estimulou a elaboração de manuais didáticos em que conteúdos e novas orientações metodológicas eram apresentados para a educação escolar. Em decorrência desse método de ensino, tornou-se urgente a necessidade de provimento das instituições de ensino no que se refere à diversificação de recursos didáticos, entre eles, encontram-se os manuais escolares.

\section{Cultura material escolar - foco nos manuais didáticos}

É importante registrar que o estudo dos manuais revela-se importante também no que se refere à reconstrução dos saberes e práticas relacionadas ao ensino das disciplinas específicas, bem como à história da formação dos professores, aspectos pertinentes à reconstrução histórica de cada ciência como disciplina escolar, conforme Bufrem, Schmidt e Garcia (2006, p.124). Na pesquisa é importante considerar, conforme Badanelli (2010), a necessidade de investigar os manuais não 
Manuais didáticos no início do século XX em Sergipe: cultura material escolar dos

grupos escolares

apenas por eles mesmos, pois apesar dos manuais escolares refletirem as intenções políticas, ideológicas, pedagógicas etc. de um determinado período, ele por si só não explica nada a respeito da sua recepção. Esse aspecto limita as pesquisas acerca dos manuais, principalmente quando se pretende compreender parte da cultura da escola. Nesse sentido, para a compreensão do que se pratica na escola, é preciso ir além dos manuais, buscando analisar outras fontes da época, próprias da cultura da escola ou mesmo de fora dela. Dessa maneira, concorda-se com Julia (2001, p.15) quando registra que a história das práticas é "a mais difícil de se reconstruir porque ela não deixa traço, o que é evidente em um dado momento tem necessidade de ser dito ou escrito?”. Em decorrência disso, torna-se necessária a busca de fontes, inclusive as não específicas do cotidiano escolar. Em relação a tal diversidade de fontes, Badanelli (2010, p.55) sugere a utilização de cadernos escolares, exames, diários de classe e fontes orais.

Em relação à adoção da perspectiva da História Cultural na pesquisa acerca dos manuais, concorda-se com Magalhães (s.d., p. 8) ao afirmar que os manuais escolares constituem um contributo fundamental, se não mesmo único, para a história cultural, seja por consistir em um exemplo de adaptação dos conteúdos, teorias e conceitos de uma matriz científica pura para uma aplicação à realidade escolar, em primeiro lugar; seja como representação e forma de acesso às práticas de ler e dar a ler, em segundo lugar.

Segundo Roger Chartier (1994), a tarefa do historiador é reconstruir as variações que diferenciam os textos nas suas formas materiais, discursivas e as diferentes interpretações construídas com base nesses discursos. Nesse sentido, as investigações deveriam atender a esses três aspectos que constituem a análise: o livro (sua materialidade), o texto (sua argumentação) e a leitura (sua interpretação e apreensão pelos leitores).

Neste trabalho de investigação acerca dos manuais presentes nos grupos escolares de Sergipe, a atenção é direcionada ao primeiro aspecto desse conjunto indicado por Chartier. O público leitor, obviamente, pode ser classificado como uma classe de alunos e as professoras dos grupos. Contudo, a leitura que tiveram dos manuais, as interpretações construídas e a apropriação que fizeram de suas ideias serão objeto de futuras investigações. Nestas pode-se verificar, por exemplo: Que tipo de influência os manuais poderiam exercer sobre alunos e docentes? Quais as ações de tais sujeitos frente às mensagens dos manuais, ou seja, as práticas decorrentes da apropriação e das relações de representação dos envolvidos? E, por fim: Qual o papel que os manuais desempenharam no desenvolvimento do processo de socialização do público escolar do início do século XX? Tais aspectos, sem dúvida, não são de fácil análise. 
Em relação à complexidade da análise das características e dos produtos da leitura e da apropriação do conteúdo do manual escolar, vale registrar o que afirma Magalhães (s.d.), segundo o qual, não há nada mais impreciso e difícil de investigar do que as atividades de leitura:

[...]. No quadro da cultura escolar, as actividades de leitura são mediatizadas pelo professor, pelo grupo alunos, são objectivadas em consonância com os fins e as funções da escola e da escolarização. Como inferir pelos exames e pelas aquisições de aprendizagem as formas e os significados da leitura? Ainda que as práticas de aprendizagem e de didáctica escolares sejam, em regra, uma aplicação de lectoescrita, que relação pedagógica e antropológica subjaz de facto entre a leitura e a escrita escolares? Se as marcas de orientação de leitura constantes dos manuais só indirectamente podem ser tomadas como informação sobre as formas e as práticas de leitura, também a transferência da leitura para a escrita escolar (ou a regressão da escrita escolar para a leitura) só indirectamente se poderá realizar. Entre o texto e a criança está o professor, entre o professor e o texto, está o programa. (MAGALHÃES, s.d., p.13).

Os grupos escolares, principalmente os do interior do Estado de Sergipe, enviavam comunicados de agradecimento à Diretoria da Instrução Pública pelo recebimento de diversos recursos didáticos e, entre eles, os manuais. Nos vários ofícios dos grupos, as principais obras que aparecem são: Ensaios de critica sobre o evolucionismo morphologico de Língua Portuguêsa, de Almachio Diniz; Combate ao Paludismo, de Dr. Peryassú; Valor, de Charles Wagner; e, Biologia Popular, de Dias Martins ${ }^{1}$. Outras obras também podem ser citadas:

[...]. A Capitania de Sergipe e suas ouvidorias do Sr. Do Prado, 1 volume [2 ilegiveis] sobre as condições da agricultura dos municipios do Estado de Sergipe Dias Martins, 1 volume - Recenseamento do Brasil em 1920, 1 volume Evolucionismo Morphologico - Almachio Diniz -, 1 volume - A educação - Jose Augusto, 1 volume - A costa das mattas e a exportação das madeiras brasileiras; 5 volumes - A fazenda e o campo - Carlos Fernandes, 2 volumes - Valor - C. Wagner; 2 volumes - Instruç̧ão Moral e Cívica - Araújo Costa; 2 volumes Manual Cívico - Araújo Costa; 3 volumes - Nossa Independência - Lemos Britto; 1 volume - A poesia de Humildade - Oliveira e Silva; 1 volume - Combate ao Paludismo - [1 ilegível]; 1 Folheto ABC - João Esteves da Silveira. [.... $]^{2}$. (GRUPO ESCOLAR, 1929).

Com exceção do livro de Ivo do Prado (A Capitania de Sergipe e suas ouvidorias) nos acervos dos antigos grupos, bem como nas instituições de pesquisa consultadas como Instituto Histórico e Geográfico de Sergipe e Arquivo Público do Estado de Sergipe, não foram localizadas as obras que aparecem na documentação dos grupos sergipanos. O encontro com os manuais ocorreu devido à busca de livros antigos em livrarias com seções de sebo. Dessa maneira, foram analisadas as seguintes obras: Valor, de Charles Wagner; Ensaios de critica sobre o evolucionismo 
Manuais didáticos no início do século XX em Sergipe: cultura material escolar dos

grupos escolares

morphologico de Língua Portuguesa, de Almachio Diniz; Gramatica Expositiva, de Eduardo Carlos Pereira; e, Meu Sergipe, de Elias Montalvão.

Parte-se do pressuposto de que os manuais escolares, em suas transformações ao longo do tempo, podem denunciar características da sociedade da época em que foram produzidos, tendo, dessa maneira, a possibilidade de representar as expectativas, os anseios bem como as mentalidades das sociedades escolarizadas. Os manuais aqui problematizados e analisados circularam nos grupos escolares sergipanos nas primeiras décadas de funcionamento de tais instituições (1911-1930).

Quanto à compreensão do que se considerava, na época, um manual escolar, a ausência de um guia de editoração de publicações relativo ao período investigado foi um fator contribuinte para as dificuldades na definição de um modelo acerca do que se convencionava classificar como manual escolar. Diante disso, nesta investigação, adotou-se como definição de manuais escolares publicações impressas voltadas para a educação escolar e adotadas pela então denominada Diretoria da Instrução Pública do Estado de Sergipe, órgão correspondente à atual Secretaria do Estado da Educação.

Uma definição relativa ao que vem a ser um manual escolar pode também ser encontrada em Bufrem, Schmidt e Garcia (2006), segundo os quais manuais escolares, livros de texto ou livros escolares são denominações com que têm sido designadas as publicações destinadas ao processo de escolarização. Os livros didáticos têm sido chamados de manuais pelo fato de, ao mesmo tempo, apresentarem um tema de estudo e sumariá-lo. Dessa maneira é que, “embora classificados como obras de referência, são mais efêmeros que outras obras do gênero, já que se desatualizam rapidamente, permanecendo, portanto, pouco tempo nas prateleiras” (BUFREM; SCHMIDT; GARCIA, 2006, p.123).

Partindo da materialidade dos manuais, dedica-se, também, nesta pesquisa, à análise do conteúdo das obras por compreender-se que tais documentos representam o conteúdo específico de uma área de conhecimento relacionada a uma determinada perspectiva pedagógica, carregando em si a configuração didática de um período. Além disso, retratam um tipo de aluno e um sujeito que se desejava formar. Os manuais escolares, historicamente, exercem papel de protagonistas na cultura da escola. Esse papel de importância, que representa o livro como algo valioso, torna-se mais evidente, segundo Ossenbarch (2010, p.117), quando se refere ao livro escolar. Segundo a autora: "Frente a los viejos libros escolares nuestra memoria nos remite a nuestra infancia y juventud, y los percibimos como objetos que han forjado de alguna manera nuestra forma de ser” (OSSENBARCH 2010, p.117). 
A investigação acerca da cultura material da escola com foco nos manuais escolares mostrase complexa. Este trabalho busca contribuir com a temática, possibilitando meios de compreensão das especificidades da cultura escolar dos grupos escolares de Sergipe. A cultura escolar de acordo com Viñao,

[...] estaría constituida por un conjunto de teorías, ideas, principios, normas, pautas, rituales, inercias, hábitos y prácticas (formas de hacer y de pensar, mentalidades y comportamientos) sedimentadas a lo largo del tiempo en forma de tradiciones, regularidades y reglas de juego no puestas en entredicho, y compartidas por sus actores, en el seno de las instituciones educativas (VIÑAO, 2002 apud MARTÍNEZ, 2007, p.46).

Os principais elementos constituintes de uma cultura escolar, segundo Antonio Viñao, seriam: os atores da comunidade escolar (professores, pais, alunos e pessoal técnicoadministrativo); os discursos (linguagens, conceitos e meios de comunicação); os aspectos organizacionais e institucionais (as práticas e rituais da ação educativa, o desenvolvimento dos alunos e a organização formal); e a cultura material da escola. Os elementos principais desta, segundo o autor,

[...] son tres los componentes fundamentales, que no únicos, a tomar en consideración al abordar el estudio de las culturas materiales de las instituciones educativas. El primero de ellos viene dado por el entorno fisico en el que se desarrollan las actividades educativas, que abarcaría tanto los espacios edificados como no edificados. El segundo de ellos incluiría el mobiliario, y el tercero englobaría, según la denominación dada por Viñao, el material didáctico y escolar (VIÑAO, 2002 apud MARTÍNEZ, 2007, p.48).

O conceito de cultura escolar utilizado nesta pesquisa relaciona-se às definições de Viñao (apud MARTÍNEZ, 2007), bem como de Julia (2001). Segundo este último, a cultura escolar consiste em um “conjunto de normas que definem conhecimentos a ensinar e condutas a inculcar, e um conjunto de práticas que permitem a transmissão desses conhecimentos e a incorporação desses comportamentos” (JULIA, 2001, p.10). Na opinião de Vinão bem como na de Julia é perceptível que a instituição escolar não se constitui apenas de determinações externas ao seu funcionamento. Como uma instituição social, a escola possui vivências intrínsecas a ela, capazes de formar e transmitir valores, visões de mundo, comportamentos, normas, conhecimentos, portanto, uma determinada cultura.

Considera-se importante explicar de que maneira tem sido compreendido pelos historiadores da educação o termo ‘cultura material escolar’. Nesse sentido, as palavras de Felgueiras (2010, p.27) são elucidativas: 
Com esse termo, oriundo da arqueologia, do materialismo histórico, recuperado pela Nova História Francesa e agora deslocado para o campo educativo, pretendemos reintroduzir a atenção aos factos do cotidiano, no que representam estruturas relativamente estáveis, que enquadram as acções dos actores e de que estes, muitas vezes, não tomam consciência. A cultura, neste contexto, é definida como "conjunto de resultados materiais, fruto das acções distintas inspiradas por uma mesma tradição”. (FELGUEIRAS, 2010, p.27).

As palavras da pesquisadora portuguesa evidenciam o significado da pesquisa a respeito da cultura material da escola para a História da Educação, hoje. Levá-la a termo exige postura acurada acerca das especificidades dos aspectos históricos dos sistemas escolares, com atenção aos seus contextos de criação e vivências bem como à cultura material presente nas escolas, que em si já refletem as condições possíveis de realização e que, evidentemente, representam as concepções de uma sociedade sobre ela própria. Com atenção, especificamente, aos livros escolares, como salienta Valdez:

[...]. Sob um olhar anacrônico, muito comum em algumas pesquisas na história da educação, a primeira idéia que se tem ao folhear livros que começaram a circular no ambiente escolar há mais de um século é a de que essas obras são ultrapassadas, fora do contexto da realidade, sem atrativos, não fazem a criança pensar, são muito sérias, não respeitam a fase da criança, etc. É verdade, os livros publicados há mais de cem anos obviamente se caracterizavam por esses dados, até porque não era tão comum discutir conceitos que se referem ao desenvolvimento infantil ou à preocupação de produzir obras de "acordo com a realidade", "textos atrativos”, que "facilitem o conhecimento”, etc. [...]. (VALDEZ 2005, p. 175).

Os manuais escolares são um dos elementos constituintes da cultura escolar e caracterizamse pela complexidade. Diversos em termos de formas e conteúdos, podem ser considerados: mercadoria, objeto cultural, veículo pedagógico. Apesar de constituírem-se em um tipo bibliográfico específico, caracterizam-se por apresentar uma diversidade de características. Como registra Justino Magalhães (s.d., p.1), “a constituição de uma epistemologia do manual escolar representa um desafio conceitual, cuja complexidade, extensível à história do livro, particulariza-se no caso do manual escolar”. Há no livro, e muito especificamente no manual escolar, dimensões de natureza: epistêmica e gnosiológica; científica e discursiva; socioantropológica. Todas elas com referência à pedagogia e à psicologia e que não se limitam ao documentalismo e à biblioteconomia. Dessa maneira, é possível concordar com Badanelli (2010) que o manual escolar tem cumprido cinco funções fundamentais, são elas: 
[...] simbólica, que representa el saber oficial; pedagógica, que transmite los saberes básicos; social, contribuye a la "inculturación" de las jóvenes generaciones; ideológica, vehicula y jerarquiza valores de modo manifiesto o latente; y política, sus contenidos son regulados por los poderes públicos de acuerdo con determinados fines escolares y extraescolares. (BADANELLI, 2010, p.50).

Apesar dos manuais escolares serem obras caracterizadas por diferentes aspectos, pode-se considerá-los como um único gênero bibliográfico do ponto de vista epistemológico e da biblioteconomia. No entanto, tais livros, uma vez tomados na sua especificidade, apresentam uma grande diversidade de tipos, segundo Magalhães:

[...]. Na medida em que simboliza uma construção cultural, estrutura o acto do conhecimento, materializa a relação pedagógica e configura o campo epistémicopedagógico da cultura escolar, o manual constitui um caso particular da produção bibliográfica e desafia a uma historiografia específica. O reconhecimento da complementaridade entre a história do livro e a história do livro escolar justifica uma abordagem serial dos manuais. (MAGALHÃES, s.d., p.6-7).

\section{Manuais didáticos nos grupos escolares de Sergipe}

O primeiro manual dos grupos escolares sergipanos do início do século XX aqui analisado intitula-se Valor, de autoria de Charles Wagner (1852-1918), traduzido para o português e publicado pelas “Edições Melhoramentos”. Conhecido como escritor moralista, pensador e pastor protestante liberal francês, Charles Wagner, nasceu em Wiberswiler (Alsácia), estudou teologia em Paris e em Estrasburgo. Frequentou as universidades de Göttingen e Heidelberg. Foi nomeado vigário pelo Diretório Luterano e, em 1877, aceitou o pastorado da Igreja Reformada Remiremont, do qual renunciou, em 1882, para estudar história e psicologia em Paris. Seus numerosos escritos sobre a espiritualidade são os de um místico independente, liberal típico do protestantismo ${ }^{3}$.

A obra Valor, em cuja parte pré-textual informa ter sido premiada pelo Ministério da Instrução Pública da França, está dividida em 17 capítulos. Não se refere aos alunos (termo), mas “A meu jovem leitor”. São os seguintes os títulos dos capítulos: I - A conquista da energia, II - O preço da vida, III - A obediência, IV - A simplicidade, V - A guarda interior, VI - A educação heróica, VII - Os começos difíceis, VIII - O esforço e o trabalho, IX - A fidelidade, X - A jovialidade, XI - A honra civil, XII - Aos enfermos, XIII - O medo, XIV - O combate, XV - O espírito de defesa, XVI - A bondade reparadora, e, XVII - Sursun corda!. Pelos títulos dos capítulos da obra é possível relacionar o seu uso às aulas de Leitura impressa que ocupavam, por exemplo, todos os dias letivos do $1^{\circ}$ e $2^{\circ}$ anos dos grupos escolares conforme grade de horários prevista no Regulamento da Instrução de 1915. 


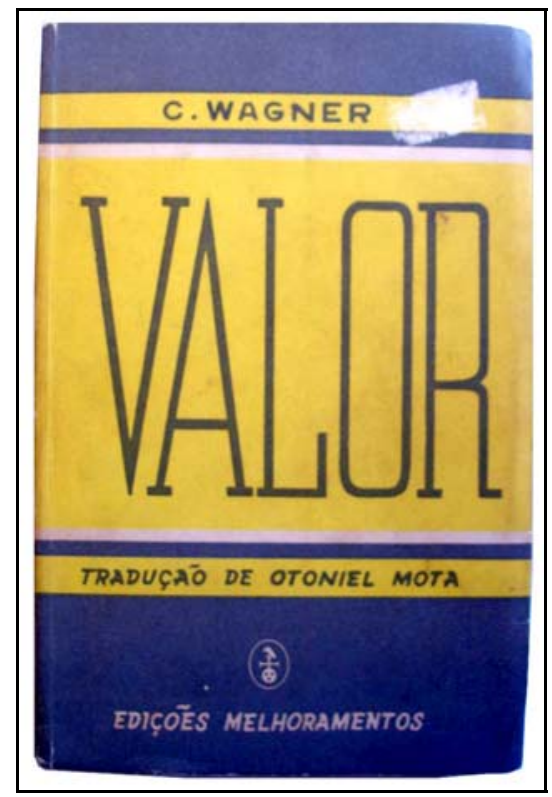

Figura 1 - Capa do livro Valor, de Charles Wagner.

Fonte: Acervo pessoal.

Trata-se de uma obra de pequeno porte, medindo 12,5 x $18 \mathrm{~cm}$. Não possui figuras. Em termos de conteúdo, gira em torno do que o autor aponta como necessário para ser homem. Segundo ele, “[...]. Para o homem o nascimento não é senão o início de um longo e laborioso desenvolvimento. E este desenvolvimento depende em parte dele mesmo, do fim que ele se propôs, dos esforços que empreende. [...]” (WAGNER, 1918, p.12). Assim, considera que o homem precisa adquirir força, energia compreendida como força moral. Compara a sociedade civilizada, mas sem força de caráter a um navio em alto-mar para cujos motores faltou carvão.

O autor dedica-se a indicar as fontes de onde se retira a energia moral. Nesse sentido, salienta a importância de se prestar atenção às coisas, rever os próprios conhecimentos, e aponta a importância da fé como chave para o mundo e a necessidade de se acreditar na justiça. Para que tal empreitada seja viável afirma que: “[...] o crescimento normal do homem exige o desenvolvimento de todo o ser, físico, intelectual e moral, sua harmoniosa reciprocidade [...]” (WAGNER, 1918, p.26), aspecto que marcou o pensamento educacional no Brasil do início do século XX.

Ao discutir a importância da obediência, procura diferenciá-la da servidão e aponta a importância da obediência até como “o único meio de fugir à servidão”, pois “A obediência é a condição indispensável para a boa vida e a liberdade” (WAGNER, 1918, p.32). A obediência a que se refere o autor diz respeito à tradição, a qual ele considera “[...] um benefício que nos é conferido, 
não uma violência que se nos faça... [...]” (WAGNER, 1918, p.33). Ao expor seu pensamento acerca da tradição, Charles Wagner assevera:

[...] Um homem que desconhecesse esse papel da tradição no desenvolvimento, cometeria a falta mais grosseira e se privaria, com deliberado propósito, do que existe de melhor. Isto não impede cada indivíduo e cada nova geração de examinar o patrimônio que os antigos lhe legaram. Longe disso: a única maneira de bem julgarem este legado e de aceitar-lhe o que há de preferível, é recebê-lo, primeiro, com deferência. (WAGNER, 1918, p.34).

A obediência por ele defendida não se trata, portanto, de obediência cega. Esta seria sinônimo de escravidão e desordem. Assim como o respeito à tradição, era perceptível a articulação com o objetivo de mudanças nos costumes e comportamentos do povo brasileiro no período. No capítulo cinco do livro, o autor destaca a necessidade de resguardo interior: “A prática da vigilância cria no homem o hábito da vida interior e a necessidade de fazer passar todas as suas obras sob os olhares da consciência” (WAGNER, 1918, p.59).

Para professores, deixava clara a importância do exemplo a ser dado aos jovens ao defender que "O homem compreende melhor o exemplo do que a regra, e segura melhor o bem em ação do que em teoria” (WAGNER, 1918, p.71). Nisto consistiria uma educação heroica, considerando o herói não aquele ilustre, mas o anônimo, que por meio de suas boas ações, bem ensinaria aos demais à sua volta. Nesse sentido, apontava a relevância da fidelidade nas relações em sociedade. De acordo com o autor:

Uma duplicidade profunda, o divórcio entre a palavra e o ato, entre a aparência e a realidade, uma espécie de diletantismo moral que faz com que sejamos, conforme a obra, sinceros ou fraudulentos, bravos ou covardes, honestos ou velhacos - eis o mal que nos rói. Que força moral pode germinar e crescer em tais condições? É preciso voltarmos a ser homens de um só princípio, uma só palavra, uma só obra, um só amor, e, para falar numa palavra, homens do dever. Aí está a força. Fora disso só há poeira de homem, areia movediça e caniços que vergam a todos os ventos. [...]. (WAGNER, 1918, p.116).

Enfim, na obra Valor, de Charles Wagner, discute-se os caminhos que levam à formação de um ser valoroso. Entre esses, considera-se as dificuldades iniciais da vida como contribuintes para a aprendizagem. O autor enfatiza que as dificuldades fazem parte da vida e são meios para um maior e melhor desenvolvimento. É possível, dessa maneira, encontrar no livro, incentivos ao leitor para reagir frente às adversidades. Para isso, Wagner (1918, p. 88) declara: “Buscai o esforço, submeteivos ao trabalho”. A esse respeito, complementa: “[...] entre todos os nossos bons amigos nenhum há melhor do que o esforço e o trabalho. [...]” (WAGNER, 1918, p.94). A crença no trabalho como fruto para alcançar uma vida valorosa aparece claramente no trecho a seguir: 
Manuais didáticos no início do século XX em Sergipe: cultura material escolar dos

grupos escolares

[...]. O movimento não é só um sinal de vida, mas uma fonte. Amaciar os músculos; exercitar o corpo; aprender a utilizar-se das mãos, dos olhos, habituar-se às fadigas, ao rigor das estações, à luta contra os obstáculos; sujeitar a inteligência aos exercícios difíceis; familiarizar a vontade com as coisas que agradam menos; domar os desejos, as emoções, as paixões; em uma palavra - domesticar e disciplinar todo o ser, eis a mais alta preocupação de quem aspira a ser um homem - Assim que nos aplicamos a esta empresa, que não é sem aspereza, percebemos que ela é fortificante. [...]. (WAGNER, 1918, p.95).

Esforço, sociedade civilizada, energia moral, crença na justiça, respeito à tradição, vigilância da consciência, a importância dos bons exemplos, a defesa do trabalho, são todos aspectos frequentes nos discursos de políticos e intelectuais no início do século XX, em Sergipe. As aulas diárias de Leitura impressa no curso primário dos grupos sergipanos, de certo contribuíram para as aprendizagens requeridas no período.

Assim, fica evidente que, por meio dos manuais é possível estudar os aspectos políticos e ideológicos de uma época bem como a história de práticas escolares. Os manuais podem ser, portanto, considerados espaços de memória, uma vez que representam a sociedade que os produziu ao evidenciar valores, comportamentos e, até mesmo, estereótipos de uma determinada sociedade ou período histórico.

Após a análise da obra Valor, de autoria de Charles Wagner e com base em Badanelli (2010) é possível afirmar o estudo desses manuais permite identificar o currículo escolar referente a diferentes disciplinas. Acrescente-se a isso, o fato de que se for proceder ao exercício da comparação da legislação educacional com os manuais escolares torna-se possível analisar as intenções políticas ou religiosas presentes em uma determinada época e em relação à transmissão de ideologias, valores, condutas, comportamentos etc. Além disso, pode-se identificar e analisar teorias pedagógicas e princípios metodológicos, tanto aqueles que predominaram durante um determinado período ou lugar e foram amplamente difundidos, quanto aquelas experiências escolares com características mais particulares.

Outra obra presente na documentação dos grupos escolares de Sergipe e aqui analisada foi Grammatica Expositiva, de Eduardo Carlos Pereira (1855-1923) e publicada pela "Secção de Obras D’O Estado de São Paulo”. O autor fez seus primeiros estudos em São Paulo, onde iniciou sua formação em Direito, a qual abandonou em decorrência do ingresso nos estudos teológicos. Foi evangélico atuante, sendo ordenado pastor presbiteriano em 2 de setembro de 1881. “A data, hoje 
em dia, é comemorada na Igreja Presbiteriana Independente como o dia do pastor, em sua homenagem” (GUTIERRES, 2010, p. 2).

Foi professor com vasta experiência em alguns dos mais respeitados colégios da época, em São Paulo: Colégio Ipiranga, Culto à Ciência, e, Escola Americana (atualmente Unidade Mackenzie). Em 1894, foi nomeado por meio de concurso público para reger a primeira cadeira de português do Ginásio Oficial do Estado de São Paulo. Esse ginásio destinava-se ao ensino secundário e habilitava seus alunos em matérias científicas e literárias. Foi nesse ambiente acadêmico que Pereira desenvolveu suas gramáticas, as quais visavam atender a necessidade de muitos professores de língua portuguesa no Brasil de sua época. Tamanha era a demanda que sua Gramática Expositiva: curso superior (1907), teve 96 edições; e a Gramática Expositiva: curso elementar (1908), 153 edições. Em 1916 produziu a Gramática Histórica que teve 10 edições (GUTIERRES, 2010).

A obra de Eduardo Carlos Pereira aqui analisada, trata-se de uma publicação de médio porte, medindo 12,5 cm x 18,5 cm. Não possui figuras. O livro era destinado aos três primeiros anos do curso superior (secundário), podendo, segundo o autor, ser usado também para as aulas de Português da Escola Normal. A presença desta obra em ofícios e relatórios de diretores de grupos escolares sergipanos deve ter, portanto, vinculação com os cuidados com a aprendizagem das professoras. Esse fato é perceptível como denota a constante distribuição aos grupos, em quantidade semelhante ao número de professoras, da Revista A Escola Primária, publicação da capital federal, o que poderia possibilitar ao corpo docente dos grupos uma constante atualização sobre o que se discutia a respeito de educação no país ${ }^{4}$.

De fato, destina-se a tal nível elevado de ensino, pois suas características físicas não se mostram condizentes com o público escolar primário. Além de muito extensa, possui espaçamento entrelinhas simples e é escrita com letras bastante pequenas, Times New Roman tamanho 11 e, por vezes, 10 .

Possui índice geral extremamente detalhado em títulos e subtítulos: Noções preliminares (1 subtítulo), Lexeologia, Fonologia, Fonética (8 subtítulos), Prosódia (8 subtítulos), Ortografia (7 subtítulos), Morfologia, Taxeonomia (60 subtítulos), Etimologia (18 subtítulos), Sintaxe (106 subtítulos), Pontuação (15 subtítulos). Além disso, possui seções de análises e exercícios analíticos, seção de quadro sinóptico e um apêndice de sintaxe e estilística e outro de composição literária. 


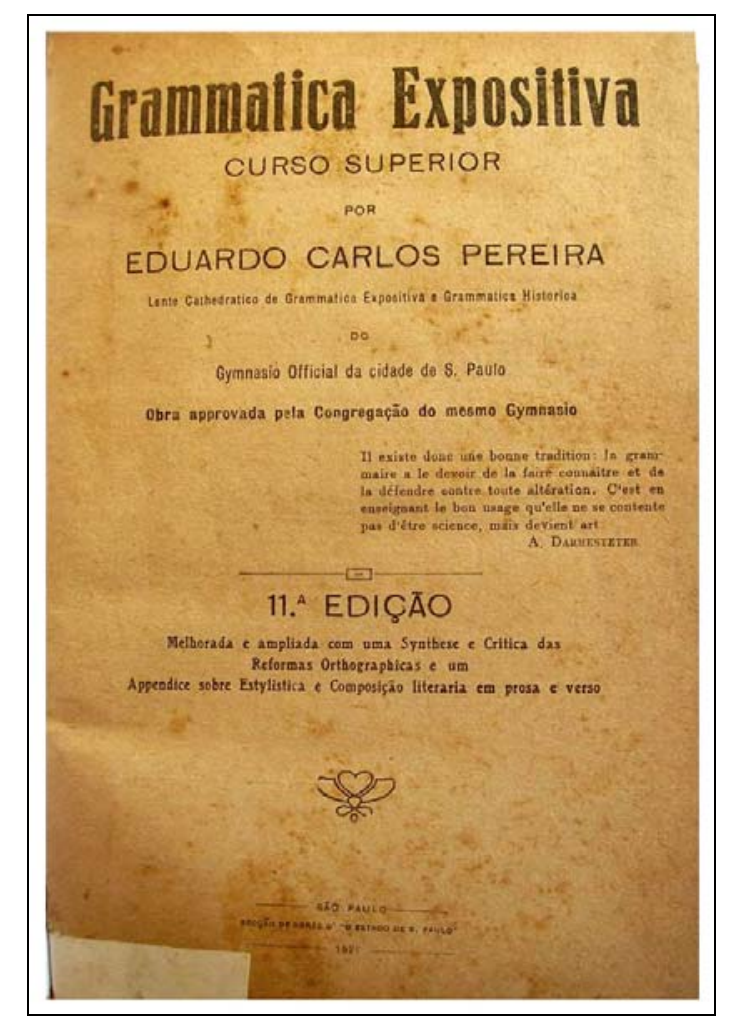

Figura 2 - Capa do livro Grammatica Expositiva - curso superior, de Eduardo Carlos Pereira. Fonte: Acervo pessoal.

Sobre Eduardo Carlos Pereira, Gutierres (2010, p. 6) comenta que “[...] tanto na área secular, como na religiosa, pode-se afirmar que ele teve, em sua época, participação ativa na vida educacional de seu povo e seu país". Acerca da sua participação na educação, "seu método de ensino consistia em ensinar com o material que ele mesmo produzia, ele seguia a orientação de seus livros, ensinando página por página, e fazendo aplicações, comentando e tirando lições sobre os ensinamentos” (GUTIERRES, 2010, p.4). A observação de Valdez (2005, p.169) acerca da produção de cartilhas de leitura para crianças, de que parte delas são frutos das próprias experiências de brasileiros “[...] como professores, diretores ou inspetores de ensino, assim como pelo fato de fazerem parte da elite intelectual do País, [...]” vale também para este manual de gramática, aqui analisado. Seu autor era professor catedrático de Gramática Expositiva e Gramática Histórica do Ginásio Oficial da cidade de São Paulo. No Brasil, professores e suas boas experiências resultaram em livros para os níveis de ensino nos quais lecionavam.

Nesse sentido, na década de 1920, em Sergipe, o presidente Graccho Cardoso (1922-26) ao autorizar a publicação de obras de intelectuais sergipanos como Armindo Guaraná, Clodomir Silva, Gumercindo Bessa e Tobias Barreto, referia-se, também, à necessidade de publicação de obras 
atentas às especificidades de Sergipe, direcionadas ao público escolar do ensino primário. Afirmava o governante:

[...] entendo tambem não ser extranho um plano pedagogico de livros para a infancia, o que pode constituir uma das theses do proximo Congresso de Professores, nos quaes as tradições sergipanas, o caracter da nossa gente, as fontes da historia regional fossem conscienciosamente hauridas, dando-se-lhes preferencia na adopção para o ensino primario e ficando o governo desde logo autorizado a editar esses trabalhos dos nossos professores, nos moldes exactos em que mais tarde irão plasmar-se as almas em formação das novas gerações. (SERGIPE. Mensagem, 1925, p. 130).

Em termos do conteúdo inserido na Grammatica Expositiva, seguindo a orientação do programa oficial de português do ensino secundário que determinava “a apreciação de trechos em que entrem provérbios, máximas e sentenças morais”, o autor informa que:

[...], enriquecemos o nosso humilde trabalho com dezenas de provérbios, máximas e ditos sentenciosos, que demos para aclarar e fixar as regras. Com taes exemplificações collimamos trez fins: a) a fixação fácil da regra pelo frisante e agradável do exemplo; b) o enriquecimento do espírito da mocidade com o legado venerável da boa e velha linguagem contida nos proloquios populares; c) a influencia salutar dos princípios morais, que eles contem. Destarte satisfazemos o excelente princípio da pedagogia alemã: aguçar o intelecto e formar o caráter. (PEREIRA, 1921, p. IV-V).

A obra Grammatica Expositiva apresenta características materiais diferentes da obra Valor. Assim como o manual Ensaios de critica sobre o evolucionismo morphologico de Língua Portuguesa, de Almachio Diniz, a seguir analisada, diz respeito a uma disciplina escolar específica. Suas dimensões físicas são maiores e a densidade do conteúdo também. Fica evidente que os manuais escolares apresentam já entre si especificidades apesar de constituírem-se, como lembra Magalhães (s.d.), em um único gênero bibliográfico em termos biblioteconômicos e epistemológicos.

Outra obra aqui analisada foi Ensaios de critica sobre o evolucionismo morphologico de Língua Portuguesa, publicada pela "Secção Graphica da Escola de Aprendizes Artífices da Bahia” e de autoria de Almachio Diniz. Nascido em 1880, na cidade de Salvador-BA, concluiu sua formação na Faculdade de Direito da Bahia, em 1899. Regeu durante alguns anos a cadeira de Filosofia do Direito desta mesma instituição, tendo consolidado a influência da Escola do Recife, sobretudo pela adoção de obras dos sergipanos Tobias Barreto e Silvio Romero. Foi membro do Instituto da Ordem dos Advogados, da Academia Baiana de Letras, da Academia Carioca de Letras, docente livre de Direito Civil da Faculdade de Direito da Universidade do Rio de Janeiro e um dos 
Manuais didáticos no início do século XX em Sergipe: cultura material escolar dos grupos escolares

fundadores da Faculdade Teixeira de Freitas, em Niterói. No fim da vida radicou-se no Rio de Janeiro.

A obra de Almachio Diniz aqui analisada trata-se de uma obra de médio porte, medindo $22 \mathrm{~cm}$ x $16 \mathrm{~cm}$. Não apresenta figuras e todo o texto possui espaçamento entrelinhas simples, escrito com letras de tamanho médio. A obra apresenta índice. Por ele se percebe que a obra divide-se em duas partes. A primeira, intitulada “As reformas”, compõe-se de sete subdivisões todas relacionadas às reformas por que passou a língua portuguesa. A segunda, denominada “O evolucionismo morphologico”, subdivide-se em nove partes, nas quais o autor analisa: a evolução estrutural do estilo português; os fundamentos biológicos estruturais dos vocábulos portugueses; a evolução das línguas; a modernidade da linguagem portuguesa bem como o valor da ancestralidade no idioma português; a sintaxe ortodoxa e a sintaxe evolucionista; a influência da biologia na filologia; e a diversidade da sintaxe brasileira em relação à portuguesa.

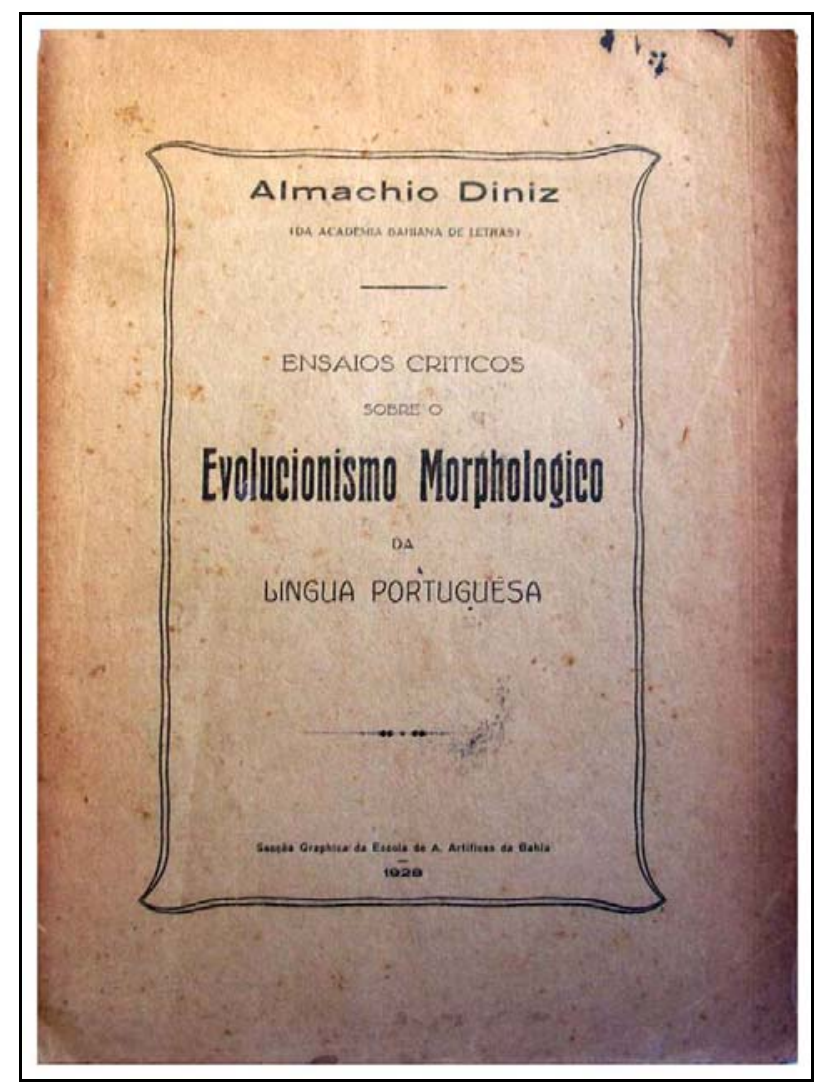

Figura 3 - Capa do livro Ensaios de critica sobre o evolucionismo morphologico de Língua Portuguesa, de Almachio Diniz.

Fonte: Acervo pessoal. 
No prefácio da $1^{\text {a }}$ edição, o autor critica a reforma de 1907 da Academia Brasileira de Letras, bem como a de 1911. Seguem as suas palavras:

Porque abandonasse eu as regras acadêmicas, dei origem á polemica que sustentei com o grammatico português Candido Figueredo, no decurso da qual mereci a censura a que já alludi. Hoje, portanto, da reforma orthographica como a usei, guardo apenas a reminiscência [...]

Quero a simplificação estructural dos vocábulos, segundo as leis naturaes da philologia, e hei de vel-a triumphante. E, no que consiste essa preferida simplificação, ao passar dos seus fundamentos scientificos e biológicos, não só, mas também dos seus effeitos graphicos na linguagem brasileira, que também procurarei definir do melhor modo, discutirei nas paginas que se vão ler. (DINIZ, 1928, prefacio da $1^{\text {a }}$ edição).

De fato o português construído no Brasil, ao longo dos quatros séculos, distinguia-se da língua de Portugal em decorrência de um desenvolvimento lexicográfico influenciado também por línguas africanas e ameríndias, com destaque para o banto, de Angola, e o Tupi, de nações indígenas locais. Esse fato é revelador de um enriquecimento linguístico criado como fruto de uma evolução distinta e autônoma em relação à antiga metrópole. O processo histórico, dessa maneira, justificava a autonomia da gramática brasileira, permeada de expressões regionais próprias.

A exemplo dos manuais anteriormente apresentados, este não apresenta elementos que pudessem ser considerados atrativos à leitura. Contudo, é possível considerar que esse aspecto não estava entre as maiores preocupações dos autores de livros no período. Da mesma forma é admissível presumir que em um contexto no qual manuais didáticos eram raros e de difícil acesso assim como outros meios de informação, o contato com tais obras já poderia em si ser considerado um atrativo para a aprendizagem. É preciso considerar, ainda, as condições de produção dos manuais na época. A produção de um livro curto, com uma quantidade menor de páginas ou uma obra sem figuras teria seus custos de fabricação reduzidos, isso poderia promover, consequentemente, maior venda.

Na investigação da cultura escolar dos grupos escolares de Sergipe, com ênfase nos manuais didáticos, a busca é pela compreensão dos eventos, dos contextos, das singularidades dos sujeitos e de suas ações. Como bem recorda Escolano Benito (2007), os historiadores do material: 
Manuais didáticos no início do século XX em Sergipe: cultura material escolar dos

grupos escolares

[...] nos movemos entre estos condicionamientos. Tratamos de buscar la relación de los objetos con sus contextos de creación y uso, intentando construir una especie de arqueología de las cosas ajustada a su genealogía. Pero también situamos los materiales en escenarios de distintos lugares y tiempos en los que aquellas invenciones se crearon y difundieron, tratando de analizar las sucesivas recepciones y adaptaciones o metamorfosis de estos objetos en otros escenarios en los que se utilizaron. Y, más aún, exhibimos estos restos arqueológicos en recreaciones determinadas culturalmente por la sensibilidad de nuestro tiempo (BENITO, 2007, p.21).

De fato, nisto consiste a história, na busca pela informação correta, procedente, em uma caminhada densa e por vezes tortuosa em busca do próximo indício. A produção do conhecimento histórico, como aponta Benito (2007, p.19) “es una práctica semiótica por excelencia” e, ao final de um processo investigativo, o relato histórico produzido pelo pesquisador consistirá em uma reconstrução dos eventos ou dos significados das coisas do passado elaborada com base nos indícios que mostraram os testemunhos que, por sua vez, mereceram a credibilidade do investigador.

A presente análise sobre a cultura material escolar dos grupos sergipanos buscou, também, atentar para o contexto de criação dos manuais escolares investigados. Dessa maneira foi possível perceber relações entre concepções sociais, políticas e pedagógicas da época de criação dos livros nas próprias obras, assim como diferenças entre os manuais escolares. A última obra examinada nesta pesquisa intitula-se Meu Sergipe, publicada pela “Tipografia Comercial de Aracaju” e de autoria de Elias Montalvão. Ela é um demonstrativo, por exemplo, de diferenças em relação aos manuais analisados anteriormente. O livro trata da história e da corografia de Sergipe e destina-se à escola primária. Na folha de rosto da obra, o autor declara a quem se destina o livro - alunos do curso primário - salientando que fez uso de uma linguagem de fácil compreensão para a criança ser capaz de aprender.

O livro está organizado em 27 capítulos. Os 12 primeiros referem-se à História. Do capítulo 13 ao 26 apresenta conteúdo relativo à corografia 5 . O último capítulo não é dedicado às disciplinas, nele, o autor apresenta uma reflexão acerca do papel do professor e do manual didático no processo escolar.

De acordo com a reforma do ensino de 1911, a partir da qual os grupos escolares foram criados em Sergipe, determinava-se também para o ensino primário a prática do método de ensino intuitivo, bem como a adoção de compêndios aprovados pela Diretoria de Instrução Pública. Os 
procedimentos, para tanto, se iniciavam com a apresentação da obra pelo autor para um processo de análise por Comissão responsável pela emissão do parecer de aceitação. Analisado em 1914 por uma comissão de professores da Escola Normal, Meu Sergipe foi aprovado por unanimidade para adoção nas escolas públicas primárias de Sergipe. Contudo, a obra só foi editada em 1916. De acordo com a comissão que analisou a obra:

O referido livro, trabalho original no estylo, é importante, pois transmite suavemente ás creanças a Historia e a Chorographia de Sergipe. Em estylo puramente synthetivo, é muito accessível á comprehensao dos alumnos do curso primário. Não é somente importante o livrinho em questão; é também patriótico, porquanto incute, de modo fácil, aos alumnos sergipanos os principaes conhecimentos históricos e chorographicos de sua pátria; e facilitam ás creanças o conhecimento da Historia Pátria é incital-as ao semtimento sublime do Patriotismo... (PARECER DA COMISSÃO apud ANDRADE, 2002, p.18).

Evidencia-se, por meio do parecer da Comissão da Escola Normal, que o manual didático apresenta aspectos considerados pertinentes para um recurso de caráter didático: sintético, acessível, de transmissão suave aos alunos dos conhecimentos históricos e corográficos. Tais aspectos ao que se percebe tornavam a obra original. De fato, a obra diferenciava-se das demais apresentadas e analisadas nesta pesquisa. A preocupação com a construção de uma linguagem de fácil compreensão para a criança do ensino primário era salientada pelo próprio autor já na folha de rosto do livro.

A partir da Figura 4, ao observar a linguagem da obra, é possível perceber que o autor lança mão do conto para narrar a história. Personagens aparecem, mas sem nome, o que interessa é o episódio e a articulação de aspectos presentes na estória com o próprio aluno (o pai, o filho, o avô). Após o relato de uma situação familiar, segue-se a parte histórica. A forma como o autor organiza o texto permite ao leitor identificar com facilidade os personagens fictícios e os reais. Tal maneira de estruturar a linguagem contribui para tornar a leitura mais agradável para crianças da escola primária. Além disso, vale salientar a construção de frases curtas e diretas o que torna a obra também uma contribuinte para o exercício da leitura. 
Manuais didáticos no início do século XX em Sergipe: cultura material escolar dos grupos escolares

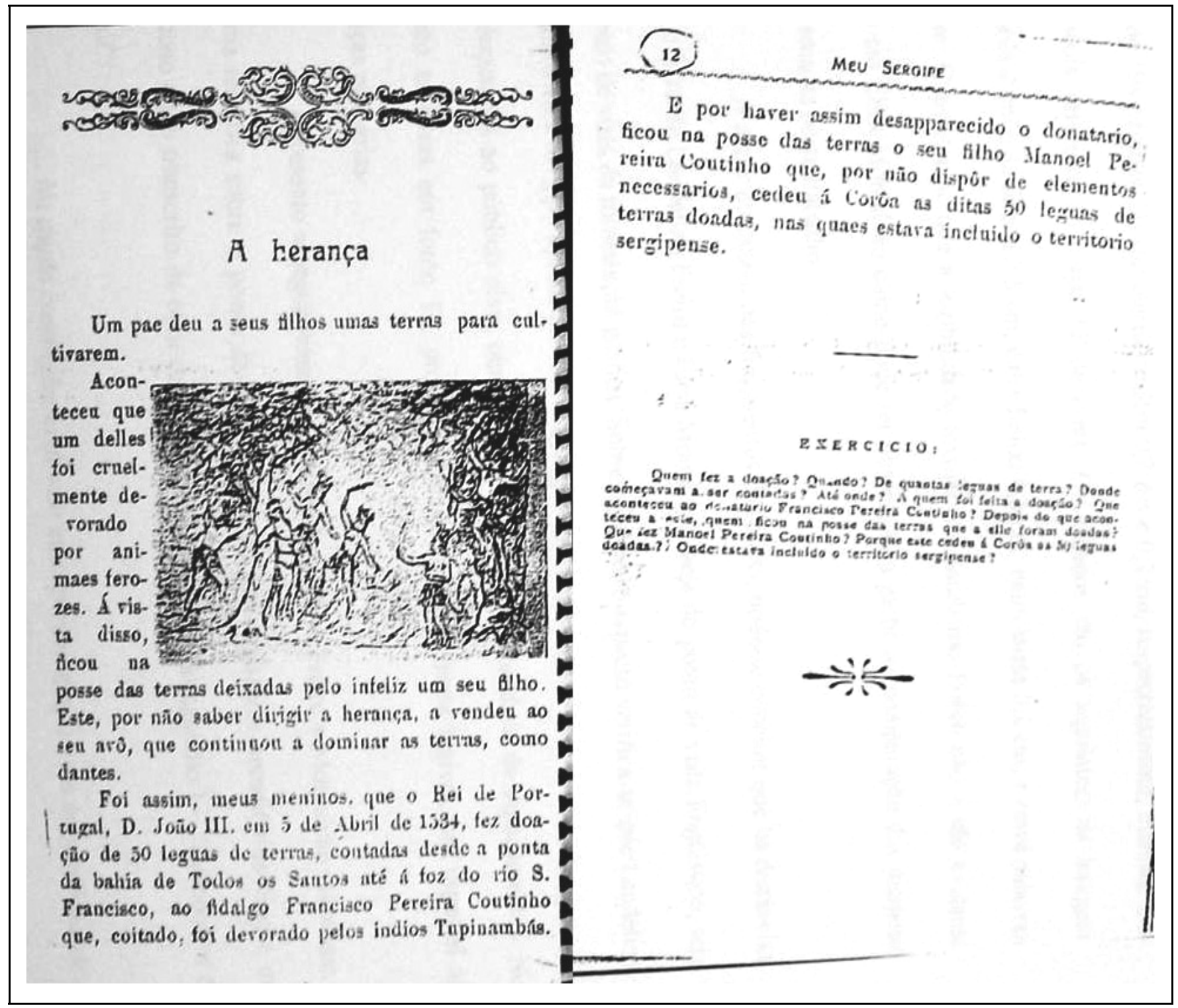

Figura 4 - Páginas 11 e 12 do livro Meu Sergipe, de Elias Montalvão. Fonte: apud ANDRADE, 2002, p. 40.

Andrade (2002) afirma que a estrutura do texto de Elias Montalvão segue o eixo políticoadministrativo em perspectiva cronológica. Os agentes históricos são os administradores públicos, os homens que fizeram a história de Sergipe. Tal fato demonstra a adoção de uma determinada postura teórica frente ao conhecimento histórico, a partir da qual o ensino é marcado pela narrativa construída sobre exemplos a serem apreendidos, admirados e seguidos por meio do estudo das ações realizadas pelos heróis considerados construtores da nação, os governantes, principalmente. 
Contudo, os títulos dos capítulos não explicitam claramente o conteúdo em termos de fatos e temporalidade. São exemplos: $O$ andarilho, $O$ achado, $O$ fujão, $O$ vapor, A recompensa, $O$ juiz, Que vergonha!!!, O nosso Hymno, O sello, O thesoiro, A obediência, A propaganda, Os retratos, Continuando, A herança, $O$ estímulo, $O$ dia de férias. Esse fato demonstra que a atenção do autor estava para além da erudição acerca da História. Havia uma preocupação pedagógica na escrita de tal história. Os títulos eram formulados de forma a atrair o aluno.

A obra Meu Sergipe estava formatada em fonte tamanho 14 da família serifa romana. Apresenta espaços irregulares com variação média de $1 \mathrm{~cm}$ e $1,5 \mathrm{~cm}$ entre as margens direita e esquerda, 0,1 cm entre as letras, $0,3 \mathrm{~cm}$ entre as linhas bem como entre as palavras. Tais aspectos podem ser considerados garantidores de uma boa fluência na leitura do texto, de acordo com Andrade (2002, p.34).

Diferente das três primeiras obras analisadas nesta pesquisa, Meu Sergipe possui uma rica iconografia. Composta por vinhetas apresentadas acima do título dos capítulos, e, ilustrações correspondentes a fotografias, cartões postais, quadro, selo e desenhos em um total de 29. Andrade (2002) registra que tais ilustrações retratam governantes do Estado, praças e prédios públicos, intelectuais sergipanos, e diferentes cenas na forma de desenhos semelhantes aos esboços produzidos por crianças na faixa etária correspondente ao ensino primário.

Uma investigação que busca conferir o papel das ilustrações, a função dos questionários e da ordenação dos textos, entre outros aspectos possíveis, enquadra-se no âmbito uma história cultural. Na obra Meu Sergipe verifica-se, por exemplo, que o autor utilizou ilustrações, variou o tipo de linguagem ao introduzir o conto como recurso linguístico, e como afirmou na apresentação da obra, de fato, fez uso de uma linguagem que se adequasse à criança.

Em relação ao método de ensino presente na obra, é possível perceber, por meio das atividades propostas e dispostas no final dos capítulos que estas se resumem aos exercícios do tipo questões-resposta. As perguntas - ligadas diretamente ao texto do capítulo e exigindo do aluno respostas que serão obtidas ao se seguir a própria sequência do texto -, denunciam uma preocupação com a aprendizagem no sentido da memorização das informações de cunho histórico contidas no texto. Ao observar a Figura 4, pode-se visualizar tal situação. Após a leitura do capítulo intitulado “A herança”, diversas perguntas são apresentadas em letras/caracteres em menor tamanho em relação ao texto base. São elas:

Quem fez a doação? Quando? De quantas léguas de terra? Donde começavam a ser contadas? Até onde? A quem foi feita a doação? Que aconteceu ao donatário Francisco Pereira Coutinho? Depois do que aconteceu a este, quem ficou na posse das terras que a elle foram doadas? Que fez Manoel Pereira Coutinho? Porque este 
Manuais didáticos no início do século XX em Sergipe: cultura material escolar dos

grupos escolares

cedeu á Coroa as 50 leguas doadas? Onde estava incluído o território sergipense? (MONTALVÃO, 1914, p.17 apud ANDRADE, 2002, p.40).

Andrade (2002) considera contradição da obra a presença de exercícios de atividades de maneira a condicionar os alunos à memorização. Contudo, acredita-se que é preciso considerar um pouco mais os pressupostos sobre os quais se assentavam a produção científica no período. Tal fato deixará evidente a pertinência da obra ao seu contexto de produção e mostrará o seu autor como um intelectual do seu tempo.

A observação da estratégia de verificação da aprendizagem dos alunos presente no livro evidencia a presença de uma pedagogia tradicional preocupada com a transmissão dos conteúdos. Esta tendência pedagógica estava presente no período de constituição do manual de Elias Montalvão. Valendo-se dela, ensinar significa transmitir conhecimentos. Os sujeitos aprendem por meio de informações sistematizadas, memorizando e repetindo exercícios. Tais pressupostos, se presentes na disciplina História, marcam um processo de ensino-aprendizagem no qual o conteúdo histórico é veiculado, principalmente, pelo texto-base ou pelo discurso do professor, tornando-se o objetivo principal do ensino a recuperação de informações e a memorização. O exercício “Responda” ou simplesmente "Exercício”, com variantes como: citar, preencher lacunas, escrever nomes, copiar informações do texto, entre outras, torna-se o eixo central das atividades. A coerência em termos historiográficos mostra-se, assim, também presente em termos pedagógicos, apesar do crescimento da influência da perspectiva do método intuitivo na época.

Dessa forma é que, como assinala Andrade:

[...] Montalvão norteia sua história através dos fatos ligados as questões políticas que marcaram o nosso Estado da sua conquista até o ano de 1913, anterior a escrita da obra, e que tem nos homens responsáveis pelo poder, assim como naqueles de destaque nacional nos campos jurídico, econômico e cultural, os motores da História. (ANDRADE, 2002, p.50).

Isso denuncia, assim como a coerência pedagógica, a lógica historiográfica com os propósitos do período e não uma contradição do livro.

No último capítulo da obra - “O dia de férias” - o autor dedica-se a salientar o papel do professor e a importância do livro como um instrumento valioso na contribuição da aprendizagem. Diante do exposto, afirma-se o caráter inovador de Meu Sergipe, conforme argumenta Andrade:

[...]. Isso pode ser constatado nas tentativas de adequar o texto às capacidades da criança, seja modificando o padrão tipográfico do período (letras e espaçamentos maiores entre linhas, adoção de ilustrações, adorno nas páginas com traços ou vinhetas), seja utilizando recursos lingüísticos supostamente dirigidos ao aluno (o 
uso do conto, emprego do diálogo, do discurso direto), ou ainda, aproximando família e escola no trabalho de educação da criança. [...]. (ANDRADE, 2002, p.47).

Nos manuais escolares também podem ser encontradas as intenções das autoridades escolares e governamentais convertidas em propósitos educativos, uma vez que os livros contêm o currículo programático transformado em textos e atividades escolares. Dessa maneira, tornam-se fontes primordiais para a compreensão da cultura escolar de um determinado contexto, ao deixar registrado em suas páginas aquilo que se desejava ensinar em uma determinada época. Mas, é importante considerar que, analisados em si mesmos, não podem revelar os meandros de tal cultura, o que implica a análise de outros achados acerca de diferentes aspectos do cotidiano escolar, até das formas de recepção das próprias mensagens contidas nos manuais.

\section{Considerações finais}

O manual didático é, sem dúvida, o mais importante recurso material integrante da tradição escolar. Este instrumento de trabalho de professores e alunos faz parte do cotidiano escolar há pelo menos dois séculos. Apesar do avanço do acesso à internet, pode-se considerá-lo o principal veículo transmissor de conhecimentos sistematizados no Brasil e, portanto, o bem cultural de maior divulgação entre os brasileiros em processo de escolarização. Em decorrência desse fato, torna-se relevante a investigação acerca dos livros escolares.

Os manuais didáticos aqui analisados podem ser compreendidos como elementos da cultura escolar dos grupos em Sergipe. Produtos e produtores de conhecimentos escolares e instituidores de modos de fazer a escolarização primária, eles contribuíram para tanto, ao servirem aos trabalhos escolares diretamente desenvolvidos com os alunos e ao possibilitarem o aprofundamento de conhecimentos por parte do corpo docente das escolas de ensino primário.

Os sujeitos, os discursos e a cultura material de uma instituição de ensino integram a sua cultura escolar. Na análise dos manuais aqui apresentados percebeu-se, em consonância com o contexto de produção das obras, a constante preocupação com: a transmissão de mensagens de incentivo ao esforço, ao trabalho, à crença na justiça; o respeito à tradição; a importância dos bons exemplos; tudo requerido pelas regulamentações do período, até para livros de gramática, em que se pode verificar solicitações para que fossem utilizados "provérbios, máximas e sentenças morais” (PEREIRA, 1921, p. IV). Percebe-se, desse modo, que os manuais escolares de diferentes áreas de conhecimentos contribuíram para a disseminação de valores cívicos e morais voltados para a formação das gerações republicanas. 
Manuais didáticos no início do século XX em Sergipe: cultura material escolar dos

grupos escolares

Parte dos manuais aqui analisados não apresenta aspectos tipográficos variados que pudessem ser considerados possíveis atrativos à leitura. Contudo, é importante avaliar que o difícil acesso às obras poderia transformar o simples contato com os livros já um estímulo ao ensino e à aprendizagem. Nesse sentido, é válido colocar em destaque a obra Meu Sergipe. Diferente das demais aqui analisadas, uma vez que possui uma rica iconografia, apresenta fonte tamanho 14 e variação linguística no intuito de proporcionar melhor adequação à criança. Tal fato deixa evidente a relevância da análise de diferentes manuais didáticos de um determinado período, com o fim de obter-se maior compreensão acerca da cultura escolar de uma determinada época.

\title{
Notas
}

\begin{abstract}
${ }^{1}$ Ver: Ofício de 5/6/28 do Grupo Escolar General Valladão à Diretoria da Instrução; Ofício de 5/6/928 do Grupo José A. Ferraz à Diretoria da Instrução; Ofício de 05/06/25 do Grupo Escolar Fausto Cardoso à Diretoria da Instrução; Ofício 35 de 27/10/1927 do Grupo Escolar Fausto Cardoso à Diretoria da Instrução; Ofício de 05/06/1928 do Grupo Escolar Severiano Cardoso à Diretoria da Instrução; Ofício 229 de 25/10/1927 do Grupo Escolar Coelho e Campos à Diretoria da Instrução; Ofício 252 de 6/6/928, do Grupo Escolar Coelho e Campos à Diretoria da Instrução; Ofício de 14/06/1928 do Grupo Escolar Silvio Romero à Diretoria da Instrução; Ofício 26, de 12/04/1929 do Grupo Escolar Olimpio Campos à Diretoria da Instrução; Ofício de 10/06/1928 do Grupo Escolar João F. de Brito à Diretoria da Instrução; Ofício de 7/6/28, do Grupo Escolar Vigário Barroso; Ofício 07/1928 do Grupo Escolar José A. Ferraz à Diretoria da Instrução; Ofício 57, de 28/10/27 do Grupo Escolar Silvio Romero à Diretoria da Instrução; Ofício 27, de 08/06/1928 do Grupo Escolar Olimpio Campos à Diretoria da Instrução.

${ }^{2}$ Ofício de 06/04/1929 do Grupo Escolar Silvio Romero para Diretoria da Instrução.

${ }^{3}$ Born in Wiberswiler (Alsace), Wagner read theology in Paris and in Strasbourg. He attended the universities of Göttingen and Heidelberg. He was appointed vicar to the pastor of Barr by the Lutheran Directory and in 1877 he accepted the pastorate of the Remiremont Reformed Church from which he resigned in 1882 to study history and psychology in Paris. /A liberal minister. / He was considered as an extreme left-wing theologian and the religious community of which he was in charge almost grew into an independent church. His numerous writings on spirituality are those of an independent mystic, typical of liberal Protestantism. Ver: Site do Musée Virtuel Du Protestantisme Français - www.museeprotestant.org

${ }^{4}$ Ofício n. 10, de 18/4/28, e de 08/04/1927 do Grupo Escolar Barão de Maroim à Diretoria da Instrução; Ofício 72, 01/12/1927 do Grupo Escolar General Valladão à Diretoria da Instrução; Ofício de 13/4/29 e n. 25, de 19/8/29 do Grupo Escolar José A. Ferraz à Diretoria da Instrução; Ofício n. 22, de 27/8/930 e n. 59, de 01/12/1927 do Grupo Escolar Manoel Luís à Diretoria da Instrução; Ofício 14/08/29 do Grupo Escolar Fausto Cardoso à Diretoria da Instrução; Ofício n. 270, de 20/10/28 e n. 301, de 18/09/929, do Grupo Escolar Coelho e Campos à Diretoria da Instrução; Ofício n. 44, de 22/07/1929, n. 45, de 27/07/1929 e n. 63, de 01/12/1927 do Grupo Escolar Olimpio Campos à Diretoria da Instrução.

${ }^{5}$ Nesta parte da obra encontram-se aspectos geográficos, tanto físicos (clima, flora, riquezas minerais) quanto humanos (aspectos constitutivos da sociedade como os poderes judiciário e executivo). Há espaço, ainda, para o destaque de vultos sergipanos a exemplo de Tobias Barreto e Sílvio Romero. Trata também das riquezas sergipanas e dos administradores públicos que contribuíram para o crescimento do Estado. (ANDRADE, 2002).
\end{abstract}

\section{Referências:}

ANDRADE, L. A. O. M. De Para formação do bom sergipano: um estudo do livro didático Meu Sergipe de Elias Montalvão (1916). 55p. Monografía (Graduação em História) - Universidade Federal de Sergipe, São Cristóvão, 2002. 
BADANELLI, A. M. La investigación histórica con manuales escolares: ventajas y limitaciones. Revista Linha. Dossiê Cultura escolar e seus suportes materiais. Florianópolis, v. 11, n. 2, p. 46-67, jul./dez. 2010.

BENITO, A. E. La cultura material de la escuela. In: BENITO, A. E (Org.). La cultura material de la escuela - en el centenário de la Junta para la Ampliacion de Estúdios, 1907-2007. Berlanga de Duero: Soria, 2007, p. 15-27.

BUFREM, L. S.; SCHMIDT, M. A.; GARCIA, T. M. F. B. Os manuais destinados a professores como fontes para a história das formas de ensinar. Revista HISTEDBR On-line, Campinas, n.22, p. 120-130, jun. 2006. Disponível em:

http://www.histedbr.fae.unicamp.br/revista/edicoes/22/index.html, acesso em 20.jan. 2011.

CHARTIER, R. Comunidades de leitores. In: CHARTIER, R. A ordem dos livros. Leitores, autores e bibliotecas na Europa entre os séculos XIV e XVIII. Brasília: UNB, 1994.

DINIZ, A. Ensaios de critica sobre o evolucionismo morphologico de Língua Portuguesa.

[Salvador]: Seção gráfica da Escola de Aprendizes Artífices da Bahia, 1928. 150p.

FELGUEIRAS, M. L. Cultura escolar: da migração do conceito à sua objetivação histórica. In: FELGUEIRRAS, M. L.; VIEIRA, C. E. (Org.). Cultura escolar, migrações e cidadania. Porto: Sociedade Portuguesa de Ciências da Educação e autores, [2010], p. 17-32.

GRUPOS ESCOLARES. Livros de correspondência oficial dos grupos escolares de Sergipe. Anos: 1925-1930.

GUTIERRES, E. A. Vida e contribuição educacional de Eduardo Carlos Pereira. SEMINÁRIO DE PESQUISA DO PPE. Anais. Universidade Estadual de Maringá, 27 e 28 de abril de 2010.

JULIA, D. A cultura escolar como objeto histórico. Tradição de Gizele de Souza. Revista Brasileira de História da Educação, Campinas, n. 1, p. 9-43, 2001.

MAGALHÃES, J. O manual escolar no quadro da história cultural: para a historiografia do manual escolar em Portugal. Disponível em http://sisifo.fpce.ul.pt/pdfs/01-Justino.pdf Acessado em: 19 jan. 2011. 20p.

MARTÍNEZ, P. L. M. La modernización de la cultura material de la escuela pública em España, 1882-1936. In: BENITO, A. E. (Org.). La cultura material de la escuela - en el centenário de la Junta para la Ampliacion de Estúdios, 1907-2007. Berlanga de Duero, Soria, 2007, p. 45-74.

MONTALVÃO, E. Meu Sergipe: ensino de História e Corografia. Aracaju: Tip. Comercial, 1916.

OSSENBACH, G. Manuales escolares y patrimonio histórico-educativo. Educatio Siglo XXI, v. 28, n. 2, p. 115-132, 2010.

PEREIRA, E. C. Grammatica Expositiva - curso superior. 11 ed. São Paulo: Seção de Obras D’O Estado de São Paulo, 1921, 425 p.

SERGIPE. Regulamento Geral da Instrucção Publica do Estado de Sergipe, expedido conforme Decreto n. 587, de 9 de janeiro de 1915. 
SERGIPE. Mensagem apresentada á Assembléa Legislativa, em 7 de Setembro de 1925, [...], pelo Dr. Maurício Graccho Cardoso, Presidente do Estado. Aracaju: Imprensa Official, 1925.

VALDEZ, D. Virtudes, instrução e diversão: a infância no Primeiro Livro de Leitura, de Felisbeto de Carvalho (1892). Pro-posições - revista da Faculdade de Educação-Unicamp. Campinas, v. 16, n. 1 (46), jan./abr. 2005, p. 167-18. 193.

WAGNER, C. Valor. 10 ed. Tradução de Otoniel Mota. São Paulo, Edições Melhoramentos, 1918.

Recebido em 30/08/2011

Aprovado em 27/11/2011. 